\title{
Harnessing the respiration machinery for high-yield production of chemicals in metabolically engineered Lactococcus lactis
}

Liu, Jianming; Wang, Zhihao; Kandasamy, Vijayalakshmi; Lee, Sang Yup; Solem, Christian; Jensen, Peter Ruhdal

Published in:

Metabolic Engineering

Link to article, DOI:

10.1016/j.ymben.2017.09.001

Publication date:

2017

Document Version

Peer reviewed version

Link back to DTU Orbit

Citation $(A P A)$ :

Liu, J., Wang, Z., Kandasamy, V., Lee, S. Y., Solem, C., \& Jensen, P. R. (2017). Harnessing the respiration machinery for high-yield production of chemicals in metabolically engineered Lactococcus lactis. Metabolic Engineering, 44, 22-29. https://doi.org/10.1016/j.ymben.2017.09.001

\section{General rights}

Copyright and moral rights for the publications made accessible in the public portal are retained by the authors and/or other copyright owners and it is a condition of accessing publications that users recognise and abide by the legal requirements associated with these rights.

- Users may download and print one copy of any publication from the public portal for the purpose of private study or research.

- You may not further distribute the material or use it for any profit-making activity or commercial gain

- You may freely distribute the URL identifying the publication in the public portal 


\section{Author's Accepted Manuscript}

Harnessing the respiration machinery for high-yield production of chemicals in metabolically engineered Lactococcus lactis

Jianming Liu, Zhihao Wang, Vijayalakshmi Kandasamy, Sang Yup Lee, Christian Solem, Peter Ruhdal Jensen

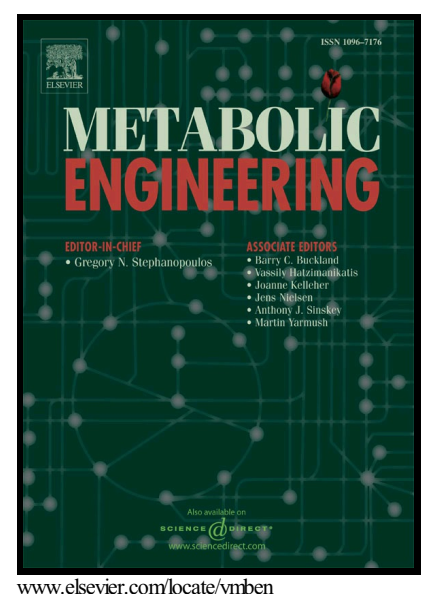

PII: S1096-7176(17)30154-4

DOI: $\quad$ http://dx.doi.org/10.1016/j.ymben.2017.09.001

Reference: YMBEN1280

To appear in: Metabolic Engineering

Received date: 13 May 2017

Revised date: 14 August 2017

Accepted date: 2 September 2017

Cite this article as: Jianming Liu, Zhihao Wang, Vijayalakshmi Kandasamy, Sang Yup Lee, Christian Solem and Peter Ruhdal Jensen, Harnessing the respiration machinery for high-yield production of chemicals in metabolically e n g ine e r e d Lactococcus lactis, Metabolic Engineering, http://dx.doi.org/10.1016/j.ymben.2017.09.001

This is a PDF file of an unedited manuscript that has been accepted for publication. As a service to our customers we are providing this early version of the manuscript. The manuscript will undergo copyediting, typesetting, and review of the resulting galley proof before it is published in its final citable form. Please note that during the production process errors may be discovered which could affect the content, and all legal disclaimers that apply to the journal pertain. 


\title{
ACCEPTED MANUSCRIPT
}

\section{Harnessing the respiration machinery for high-yield production of chemicals in metabolically engineered Lactococcus lactis}

Jianming Liu ${ }^{1}$, Zhihao Wang ${ }^{1}$, Vijayalakshmi Kandasamy ${ }^{1}$, Sang Yup Lee ${ }^{2}$, Christian Solem ${ }^{1 *}$, Peter Ruhdal Jensen ${ }^{1 *}$

${ }^{1}$ National Food Institute, Technical University of Denmark, DK-2800 Kongens Lyngby, Denmark.

${ }^{2}$ Department of Chemical and Biomolecular Engineering (BK21 Plus Program), Korea Advanced Institute of Science and Technology (KAIST), Daejeon 305-701, Republic of Korea.

*Christian Solem. National Food Institute, Technical University of Denmark, DK-2800 Kgs. Lyngby, Denmark; telephone: +45 45252510; fax: +45 45932809; e-mail: chso@ food.dtu.dk

*Corresponding author. Peter Ruhdal Jensen National Food Institute, Technical University of Denmark, DK-2800 Kgs. Lyngby, Denmark; telephone: +45 45252510; fax: +45 45932809; e-mail: perj@food.dtu.dk

\begin{abstract}
When modifying the metabolism of living organisms with the aim of achieving biosynthesis of useful compounds, it is essential to ensure that it is possible to achieve overall redox balance. We propose a generalized strategy for this, based on fine-tuning of respiration. The strategy was applied on metabolically engineered Lactococcus lactis strains to optimize the production of acetoin and $(R, R)-2,3$-butanediol (R-BDO). In the absence of an external electron acceptor, a surplus of two NADH per acetoin molecule is produced. We found that a fully activated respiration was able to efficiently regenerate $\mathrm{NAD}^{+}$, and a high titer of $371 \mathrm{mM}(32 \mathrm{~g} / \mathrm{L})$ of acetoin was obtained with a yield of $82 \%$ of the theoretical maximum. Subsequently, we extended the metabolic pathway from acetoin to R-BDO by introducing the butanediol dehydrogenase gene from Bacillus subtilis. Since
\end{abstract}




\section{ACCEPTED MANUSCRIPT}

one mole of NADH is consumed when acetoin is converted into R-BDO per mole, only the excess of NADH needs to be oxidized via respiration. Either by fine-tuning the respiration capacity or by using a dual-phase fermentation approach involving a switch from fully respiratory to nonrespiratory conditions, we obtained $361 \mathrm{mM}(32 \mathrm{~g} / \mathrm{L}) \mathrm{R}-\mathrm{BDO}$ with a yield of $81 \%$ or $365 \mathrm{mM}$ (33 g/L) with a yield of $82 \%$, respectively. These results demonstrate the great potential in using finelytuned respiration machineries for bio-production.

\section{Keywords}

Respiration capacity; Hemin; Lactococcus lactis; Acetoin; $(R, R)$-2,3-butanediol

\section{Introduction}

When selecting a microorganism to be used as a cell factory for production of a particular compound, there are many factors that need to be taken into consideration, e.g., the robustness, the metabolic flexibility and the ability to grow on cheap feedstocks (Lee and Kim, 2015; Nielsen and Keasling, 2016; Stephanopoulos, 2007). It is also important to ensure that production of the desired compound enables redox balance. The importance of this has been demonstrated for various engineered microorganisms, e.g., Escherichia coli producing 1-butanol or organic acids (Shen et al., 2011; Kim et al., 2015), Saccharomyces cerevisiae producing D-lactic acid (Baek et al., 2016), Lactococcus lactis producing (S,S)-2,3-butanediol (S-BDO) (Liu et al., 2016a), and Corynebacterium glutamicum producing L-valine (Hasegawa et al., 2013). The redox balance is readily attained for the compounds mentioned above without involving an external electron acceptor. However, this is not always possible and an external electron acceptor is needed for the cells to regenerate $\mathrm{NAD}^{+}$for the biosynthesis of more oxidized chemicals. Alternatively, various strategies can be used, such as the co-production of different compounds (Gaspar et al., 2011), the simultaneous utilization of different substrates (Wei et al., 2013), the use of transhydrogenase (Choi et al., 2014) and NADH oxidase (NOX) (Liu et al., 2016b). The problems associated with these 


\section{ACCEPTED MANUSCRIPT}

strategies are that they are not easily generalized, and they could complicate the engineering strategy or downstream processing for product recovery. Although the NOX, which relies on oxygen as an electron acceptor, has been widely used for regenerating $\mathrm{NAD}^{+}$for producing compounds like acetoin, meso-2,3-butanediol (m-BDO) and $(R, R)$-2,3-butanediol (R-BDO) in Bacillus subtilis and S. cerevisiae (Kim and Hahn, 2015; Zhang et al., 2014), it is difficult to precisely control the NOX activity. In addition, a too high activity would drain most of the available $\mathrm{NADH}$ and thus reduce the yield of BDO. Currently, most processes developed for BDO production rely on keeping the oxygen tension low to prevent this problem (Biswas et al., 2012; Fu et al., 2014; Li et al., 2010; Li et al., 2015; Lian et al., 2014; Wang et al., 2012; Xu et al., 2014). However, controlling the oxygen tension can be challenging, especially in large-scale fermenters (Zhu et al., 2011). Therefore, there is an urgent need for more robust approaches for fine-tuning the amount of reducing power available.

Respiration capable microorganisms often regulate the $\mathrm{NADH} / \mathrm{NAD}^{+}$ratio via respiration. When $\mathrm{NADH}$ is oxidized into $\mathrm{NAD}^{+}$, its electrons are usually transferred to oxygen while protons are pumped across the cell membrane. The resulting proton gradient can then drive ATP formation via oxidative phosphorylation as well as various transport processes (Lane, 2010). Therefore, tampering with the respiration capacity could potentially affect both the NADH/NAD ${ }^{+}$and the ATP/ADP ratio, as demonstrated for E. coli by Zhu et al. (Zhu et al., 2011), which could have negative effects on biomass accumulation and growth, and eventually on productivity. For this reason, it would be an advantage to work with a microorganism, which has less coupling between NADH oxidation and ATP production, e.g., Lactococcus lactis. L. lactis is a lactic acid bacterium, which normally relies on a fermentative metabolism, but it can respire when hemin, an essential cofactor of cytochrome oxidase, is present (Koebmann et al., 2008; Tachon et al., 2010). Still most of the ATP is generated via substrate level phosphorylation even under respiratory conditions (Koebmann et al., 2008; 


\section{ACCEPTED MANUSCRIPT}

Garrigues et al., 2006). This characteristic indicates that it might be possible to use respiration to oxidize surplus NADH without interfering with the cellular ATP/ADP ratio and thereby growth.

In the current study, we test this hypothesis and modulate respiration by changing the hemin concentration. Focus is on the compounds acetoin and R-BDO, which differ in the amount of reducing power needed for their formation. As a chassis for producing these compounds, we used a metabolically engineered $L$. lactis, where all the main NADH-consuming competitive pathways were eliminated, including three lactate dehydrogenase homologs (LDH), the alcohol dehydrogenase (AdhE), two butanediol dehydrogenases (ButBA), the soluble NADH oxidase (NoxE), and the phosphotransacetylase (PTA). We demonstrate that high-yield production of the two compounds is achieved, either by fine-tuning respiration or by using a dual phase fermentation approach involving a switch from fully-active respiration to anaerobic fermentation. The strategy developed appears robust, and is useful for adjusting the reducing power available.

\section{Materials and methods}

\subsection{Strains and plasmids}

L. lactis subsp. cremoris MG1363 (Gasson, 1983) and its derivatives were used for the studies. Strain Ace001 is a derivative of L. lactis MG1363, where the genes encoding LDH, PTA, AdhE and ButBA have been inactivated (Liu et al., 2016b). For deleting various genes in L. lactis, the plasmid pCS1966 (Solem et al., 2008) was used. The plasmid pTD6 (Solem et al., 2013) was used to express butanediol dehydrogenase BsBdh from B. subtilis. The plasmid proGFP was used to express a redox sensitive green fluorescent protein (roGFP), roGFP1-R12 (Cannon and Remington, 2006) in order to assess the intracellular oxidative stress of L. lactis. All the constructed strains and plasmids are listed in Table 1.

\subsection{Cultivation conditions}




\section{ACCEPTED MANUSCRIPT}

L. lactis MG1363 and its derivatives were cultured in a modified version of the defined SA medium (Jensen and Hammer, 1993) supplemented with different amounts of glucose at $30{ }^{\circ} \mathrm{C}$. The medium was modified by adding $0.2 \%(\mathrm{w} / \mathrm{v})$ yeast extract (YE). When needed, $5 \mu \mathrm{g} / \mathrm{ml}$ of tetracycline and chloramphenicol were included in the medium. When needed, hemin was added to the medium to a final concentration of $0.2-10 \mu \mathrm{g} / \mathrm{ml}$. Growth and fermentation were carried out in either shake flasks or bioreactors. For shake flask culturing, 250-ml flasks containing $30 \mathrm{ml}$ of medium were used, and the shaking speed applied was $200 \mathrm{rpm}$. The bioreactors (Sartorius Biostat Q) with a $500 \mathrm{ml}$ working volume were used with a stirring speed of $200 \mathrm{rpm}$ and a constant aeration rate of $1.0 \mathrm{vvm}$ (gas volume per unit of liquid volume per minute). For the dual phase fermentations, the aerobic fermentation proceeded for $25 \mathrm{~h}$, after which aeration stopped. Subsequently, the culture was sparged with $\mathrm{N}_{2}(1.0 \mathrm{vvm}$ for $0.5 \mathrm{~h})$.

\subsection{DNA manipulations}

Electrocompetent cells of $L$. lactis were made as previously described (Holo and Nes, 1989). The $L$. lactis MG1363 derivative Ace001, carrying deletions in the three lactate dehydrogenase (ldh, ldhX, $l d h B)$, the phosphotransacetylase (pta), the alcohol dehydrogenase ( $a d h E)$ and the butanediol dehydrogenase (butBA) genes is described elsewhere (Liu et al., 2016b). Ace001 was further modified by deleting the gene encoding the NADH oxidase (noxE). To facilitate the process we introduced a thermosensitive plasmid (pCS4564) (Liu et al., 2016a) expressing LDH from E. coli into L. lactis Ace001 to get the strain Ace002. USER ${ }^{\mathrm{TM}}$ cloning technology (Geu-Flores et al., 2007) was used to insert the upstream and downstream ( $800 \mathrm{bp}$ ) of noxE into the plasmid pCS1966 to make the recombinant plasmid pCS4257. The primers used are listed in Table S1. The plasmid pCS4257 was then introduced into strain Ace002, where the successful integration gave rise to erythromycin resistance. Subsequently, counter selection was carried out in the presence of 5fluoroorotate (5-FO) to select for the resistant strain of 5-FO, where excision and loss of the 


\section{ACCEPTED MANUSCRIPT}

plasmid occurred (Solem et al., 2008). The resulting strain was designated Ace003 (Ace002

$\Delta n o x E)$. The strain AceN is a derivative of Ace003, which has lost the thermosensitive pCS4564 by incubation at $35^{\circ} \mathrm{C}$, which is a temperature that is non-permissive for replication. The codonoptimized version of BsBdh gene ( $b d h A)$ (GenScript, Piscataway, USA) from B. subtilis was used for biosynthesis of R-BDO. The complete sequence of the synthetic gene is shown in Table S2.

\subsection{Quantification of metabolites and evaluation of the intracellular redox status}

Cell growth was regularly monitored by measuring the optical density at $600 \mathrm{~nm}\left(\mathrm{OD}_{600}\right)$. The quantification of glucose, lactate, acetate, acetoin, R-BDO and m-BDO was carried out using a high-pressure liquid chromatography system (HPLC) equipped with a Bio-Rad Aminex HPX-87H column and a Shodex RI-101 detector (Tokyo, Japan). The mobile phase consisted of $5 \mathrm{mM}$ ( $\mathrm{mmol} / \mathrm{L}) \mathrm{H}_{2} \mathrm{SO}_{4}$ and the flow rate was set at $0.5 \mathrm{ml} / \mathrm{min}$. The column oven temperature was $60^{\circ} \mathrm{C}$. To measure the NADH/NAD ${ }^{+}$ratio, samples were taken from an exponentially growing culture of L. lactis at an $\mathrm{OD}_{600}$ of 0.6 , quenched using liquid nitrogen and subsequently stored at $-20^{\circ} \mathrm{C}$ until measuring. The extraction and quantification of $\mathrm{NADH}$ and $\mathrm{NAD}^{+}$were performed using the $\mathrm{NAD}^{+} / \mathrm{NADH}-\mathrm{Glo}^{\mathrm{TM}}$ Assay kit (Promega, Madison), following the instructions from the supplier.

To evaluate the intracellular redox status, $40 \mathrm{ml}$ culture samples at an $\mathrm{OD}_{600}$ of 1.5 were harvested by centrifugation at $6000 \mathrm{rpm}$ for $10 \mathrm{~min}$. Cells were re-suspended in $0.5 \mathrm{ml}$ fresh SAL medium. The excitation spectrum was determined using a Plate Reader (Infinite M200 PRO), where the emission wavelength was fixed at $508 \mathrm{~nm}$. For more details see Chen et al., 2011. To count the number of live cells of AceN and Ace001, we collected samples from the two cultures at the time point of $30 \mathrm{~h}$ and diluted to the same $\mathrm{OD}_{600}$ using fresh medium. Then a suitable volume of cells was plated on the surface of petri dishes, $2 \mu \mathrm{g} / \mathrm{ml}$ of hemin was added for the growth of AceN.

\section{Results and discussion}




\section{ACCEPTED MANUSCRIPT}

\subsection{Inactivation of all the major $\mathrm{NAD}^{+}$-regenerating pathways in L. lactis}

In order to investigate whether $L$. lactis is able to use respiration for efficient regeneration of NAD ${ }^{+}$, it is advantageous to eliminate the alternative ways for its regeneration. In L. lactis, the enzymes that are mainly responsible for regenerating $\mathrm{NAD}^{+}$include lactate dehydrogenase (LDH), alcohol dehydrogenase (AdhE), butanediol dehydrogenase (ButBA) and NADH oxidase (NoxE). Previously, we have described a homo-acetoin producer, L. lactis Ace001, carrying deletions in the genes encoding LDH, PTA, AdhE and ButBA (Liu et al., 2016b). Ace001 does not grow anaerobically but can grow aerobically due to the endogenous NoxE activity. However, this strain is difficult to manipulate genetically, as the transformation efficiency is reduced, when preparing the competent cells under aerobic conditions (Liu et al., 2016a). To address this problem, we introduced a plasmid with a thermosensitive replicon expressing LDH sourced from $E$. coli (pCS4564) into Ace001, and this resulted in strain Ace002, which grew anaerobically. Subsequently we deleted the nox $E$ gene and eliminated pCS4564 by aerobic incubation at $35^{\circ} \mathrm{C}$ in the presence of hemin. The final strain was designated AceN and the genotypes of the strains can be seen in Table 1.

In the strain AceN, almost all the competitive pathways leading away from the pyruvate node were inactivated to block formation of lactate, ethanol, acetate and formate. Formate could not be formed under the aerobic conditions used, due to oxygen inhibiting the pyruvate formate lyase (PFL) (Melchiorsen et al., 2002). Therefore, the main carbon flux was almost fully redirected towards acetoin (Fig. 1). Due to its inability to regenerate NAD ${ }^{+}$, AceN was unable to grow under anaerobic or aerobic conditions without respiration. We thus created a respiration-dependent platform strain, which could be studied further.

\subsection{Effect of hemin concentrations on cellular performance}

L. lactis is not able to synthesize hemin, an essential cofactor of the cytochrome oxidase (Fig. 1). Therefore, exogenous hemin needs to be added before respiration becomes active (Pedersen et al., 


\section{ACCEPTED MANUSCRIPT}

2012). Before investigating the role of respiration on the cofactor balance and on chemicals production, we first tested the effect of hemin concentration on the cellular performance. Since hemin is an iron-containing protoporphyrin, high levels of hemin could be potentially toxic for the cells due to radical formation via the Fenton reaction (Kumar and Bandyopadhyay, 2005). We did not observe an inhibitory effect when the hemin levels were below $7 \mu \mathrm{g} / \mathrm{ml}$, whereas $10 \mu \mathrm{g} / \mathrm{ml}$ of hemin resulted in a significantly slower growth (Fig. 2). It is well-documented that activation of respiration can result in a higher biomass yield (Duwat et al., 2001; Koebmann et al., 2008), which we also observed here. The final cell density measured by $\mathrm{OD}_{600}$ increased from $1.8(0.63 \mathrm{gDW} / \mathrm{L})$ without hemin to $2.4(0.84 \mathrm{gDW} / \mathrm{L})$ in the presence of hemin (Fig. 2).

Previously, we have found that the genes required for respiration, such as noxAB, menABCDEFHX, cydABCD and a hemin uptake operon (fur), were expressed constitutively regardless of the presence of hemin, and this indicates that respiration is functional once hemin is available from the environment (Liu et al., 2016a). Hemin uptake is a facilitated process, and several proteins are involved (Maresso et al., 2006). The finding, that a high hemin concentration has a negative effect on growth, is interesting, since L. lactis is equipped with regulatory systems to ensure hemin homeostasis, e.g., the $h r t R B A$ operon encodes an efflux pump that is essential for preventing toxic intracellular build-up of hemin (Lechardeur et al., 2012).

Under normal conditions, the main function of the $\left(\mathrm{F}_{1} \mathrm{~F}_{0}\right)$-ATPase in L. lactis is to translocate protons across the cytoplasmic membrane at the expense of ATP and to establish the essential proton gradient (Koebmann et al., 2000). It has been shown that when respiration is active, the flow of electrons through the respiratory chain also can result in proton extrusion, and thereby reduce or eliminate the drain on cellular ATP for establishing the proton gradient by the $\left(\mathrm{F}_{1} \mathrm{~F}_{0}\right)$-ATPase (Blank et al., 2001). This can partly explain the higher biomass yield observed for respiring $L$. lactis. It is essential to note that for L. lactis, normally less than $10 \%$ of the carbon flux is used for 


\section{ACCEPTED MANUSCRIPT}

biomass formation (Cocaign-bousquet et al., 1996; Kleerebezem et al., 2000). However, the higher biomass achieved under respiratory conditions could be beneficial for productivity, when L. lactis is used as a cell factory for producing various chemicals.

\subsection{Respiration can efficiently regenerate $\mathrm{NAD}^{+}$}

We examined the growth of strain AceN in the presence of different concentrations of hemin. Fig. 3A shows that the growth of AceN was hemin-dependent as expected, and that the growth rate increased from $0.55 \mathrm{~h}^{-1}$ at $0.5 \mu \mathrm{g} / \mathrm{ml}$ of hemin to $1.09 \mathrm{~h}^{-1}$ at $2.0 \mu \mathrm{g} / \mathrm{ml}$ of hemin. At an initial glucose concentration of $43 \mathrm{mM}$, the final cell density reached was $4.1\left(\mathrm{OD}_{600}\right)$ in the presence of $2 \mu \mathrm{g} / \mathrm{ml}$ hemin, while the $\mathrm{OD}_{600}$ was only 2.3 with $1.5 \mu \mathrm{g} / \mathrm{ml}$ hemin and 1.7 with $1.0 \mu \mathrm{g} / \mathrm{ml}$ hemin. Increasing the hemin levels further to $3 \mu \mathrm{g} / \mathrm{ml}$ did not result in any further changes in either the growth rate or the biomass density. We also monitored the fermentation profile of the cultures with 1.0 or $2.0 \mu \mathrm{g} / \mathrm{ml}$ of hemin. When the initial hemin level was set at $2.0 \mu \mathrm{g} / \mathrm{ml}$, all the glucose (43 $\mathrm{mM}$ ) could be metabolized within $8 \mathrm{~h}$ and $34 \mathrm{mM}$ acetoin accumulated ( $80 \%$ of the theoretical maximum yield), while the glucose uptake and acetoin formation rates were significantly lower at $1.0 \mu \mathrm{g} / \mathrm{ml}$ hemin, presumably due to poorer growth (Fig. 3B). The effect of hemin on growth also correlated well with the intracellular ratio of $\mathrm{NADH} / \mathrm{NAD}^{+}$, which decreased from 0.11 at $0.5 \mu \mathrm{g} / \mathrm{ml}$ of hemin to 0.05 at $2.0 \mu \mathrm{g} / \mathrm{ml}$ of hemin (Fig. 3C).

These data demonstrate that tuning the hemin concentration is a convenient way to regulate the intracellular NADH/NAD ${ }^{+}$ratio, which in turn affects the cellular growth and the metabolic capabilities. The growth rate of $1.0 \mathrm{~h}^{-1}$, which we achieved in the presence of hemin from 1 to 3 $\mu \mathrm{g} / \mathrm{ml}$, was close to that of the non-respiring wild type in the same medium. Zhu et al. (Zhu et al., 2011) previously manipulated the respiratory capacities of an engineered $E$. coli strain, which had lost the capacity for synthesizing coenzyme Q1 (the electron transfer in the respiratory system), and 


\section{ACCEPTED MANUSCRIPT}

found that the strain performance correlated well with Q1 supplementation. This strain could produce ethanol under aerated conditions, however, the growth rate and the biomass yield were seriously affected at low Q1 concentrations, as the main source of ATP was no longer oxidative phosphorylation. In L. lactis most of the ATP is generated through substrate level phosphorylation, and this allows us to design a suitable platform, where ATP generation and respiration could be uncoupled.

From our experiments, it seemed that $2 \mu \mathrm{g} / \mathrm{ml}$ hemin was sufficient to fully activate respiration and drive efficient growth-coupled production of acetoin as the sole product (Fig. 3A-C). However, these experiments were carried out at relatively low cell densities due to the low glucose concentration used (43 mM). At higher cell densities, it is possible that $2 \mu \mathrm{g} / \mathrm{ml}$ of hemin is insufficient to fully activate respiration in all cells, and that a higher concentration of hemin is needed. We tested this in medium containing a ten times higher initial concentration of glucose (450 $\mathrm{mM}, 81 \mathrm{~g} / \mathrm{L}$ ), and found that $5 \mu \mathrm{g} / \mathrm{ml}$ of hemin supported the best overall growth and highest biomass accumulation $\left(\mathrm{OD}_{600}\right.$ of 12.1). Below $\mathrm{OD}_{600}$ of 1.2, no difference in growth was observed when the hemin concentration was varied between $1 \mu \mathrm{g} / \mathrm{ml}$ and $6 \mu \mathrm{g} / \mathrm{ml}$, however beyond this $\mathrm{OD}_{600}$, an effect by the concentration of hemin became apparent (Fig. 3D).

\subsection{Respiration is more efficient at regenerating $\mathrm{NAD}^{+}$when compared to the NOX}

As discussed above, both respiration and NOX can regenerate $\mathrm{NAD}^{+}$. Therefore, we decided to compare the efficiency of the fermentation process using strains Ace001 and AceN, which rely on NOX activity and respiration for growth, respectively. The fermentation was carried out using bioreactors with high initial glucose concentration (450 mM, $81 \mathrm{~g} / \mathrm{L}$ ), and $5 \mu \mathrm{g} / \mathrm{ml}$ hemin was included in the medium for strain AceN, to fully activate respiration (see above). The final cell density $\left(\mathrm{OD}_{600}\right)$ for the Ace001 culture was 9.5 and the initial glucose could not be completely 


\section{ACCEPTED MANUSCRIPT}

consumed within $48 \mathrm{~h}$ (191 mM, $34 \mathrm{~g} / \mathrm{L}$ glucose left). The final titer of acetoin was $201 \mathrm{mM}(18$ $\mathrm{g} / \mathrm{L})$. In contrast, AceN grew to a higher cell density with the final $\mathrm{OD}_{600}$ of 14.1. All the glucose was consumed within $48 \mathrm{~h}$, leading to the formation of $371 \mathrm{mM} \mathrm{(32} \mathrm{g/L)} \mathrm{acetoin.} \mathrm{The} \mathrm{yield} \mathrm{for}$ acetoin production was as high as $82 \%$ of the theoretical maximum.

The improved production of acetoin in the presence of respiration on one hand could be attributed to the higher biomass, on the other hand, it has been reported that respiration can reduce oxidative stress and increase bacterial survival ability (Duwat et al., 2001). To assess whether oxidative stress could be involved, we expressed a redox-sensitive GFP (roGFP1-R12) in both Ace001 and AceN, individually. According to a study by Cannon and Remington, 2006, the green fluorescent protein variant roGFP1-R12 is a very suitable candidate for evaluating the intracellular redox status of living cells. By measuring excitation at around $400 \mathrm{~nm}$ and $475 \mathrm{~nm}$, Chen et al., 2013 found that it was possible to evaluate the redox status of L. lactis grown at different temperatures. We introduced the redox sensor in the two strains, resulting in the derivatives Ace001R and AceNR, and then used the same approach to evaluate their intracellular redox status when grown under aerobic conditions. The results are shown in Table S3 (the excitation spectrum in Fig. S1). The ratio of excitation intensity was calculated to be 2.17 for Ace001R and 1.55 for AceNR, which indicated that the oxidative stress was indeed lower for the respiratory strain. In addition, the NADH/NAD ${ }^{+}$ ratio and the number of viable cells (Table S4) were determined for the two cultures and it was found that the AceN culture had lower NADH/NAD ${ }^{+}$ratio and more live cells than the Ace001 culture. This indicates that the NOX activity in Ace001 is less efficient at regenerating $\mathrm{NAD}^{+}$in the selected experimental condition, and that respiration can indeed protect against oxidative stress.

\subsection{Fine-tuning of respiration for high-yield production of R-BDO}

As we demonstrated above, a fully active respiration can efficiently regenerate $\mathrm{NAD}^{+}$and allow for high yield production of acetoin from glucose. However, when producing compounds more reduced 


\section{ACCEPTED MANUSCRIPT}

than acetoin, it may not be desirable to have a fully active respiration, since this would deplete all of the NADH available. To test the usefulness of respiration on the production of this kind of compound, we constructed a strain able to produce the $(R, R)$-stereoisomer of butanediol (R-BDO), which can be derived from acetoin via reduction. The 2,3-butanediol dehydrogenase BsBdh from Bacillus subtilis, which is able to catalyze the formation of R-BDO enantiomer from acetoin (Yan et al., 2009), was introduced into strain AceN, giving rise to strain RBDO (Fig. 1). Since BsBdh consumes one of the two NADH/glucose formed in glycolysis, one $\mathrm{NAD}^{+}$has to be regenerated using respiration. To achieve fast growth as well as a high-yield production of R-BDO, we found that fine-tuning of the respiration capacity was necessary. The growth of the RBDO strain, as expected, remained hemin-dependent, but it grew significantly better than AceN under the same conditions (Fig. 5). In the presence of $1.0 \mu \mathrm{g} / \mathrm{ml}$ hemin, the cell density $\left(\mathrm{OD}_{600}\right)$ of RBDO was 3.9 after $6.5 \mathrm{~h}$, while it was only 1.7 for AceN, which demonstrated that BsBdh was able to regenerate $\mathrm{NAD}^{+}$efficiently. We found that most of the glucose was converted into R-BDO in the presence of $1.0 \mu \mathrm{g} / \mathrm{ml}$ of hemin and $43 \mathrm{mM}$ R-BDO was synthesized from $54 \mathrm{mM}$ glucose with the yield close to $80 \%$ of the theoretical maximum. In the presence of $3.0 \mu \mathrm{g} / \mathrm{ml}$ of hemin, large amounts of acetoin were formed (27 mM acetoin) and the yield of R-BDO dropped dramatically to $26 \%$. These results clearly indicated that there was a need for fine-tuning the respiration capacity.

In a previous and similar study, we investigated the effect of hemin on an engineered L. lactis strain with the aim to produce (3S)-acetoin (Liu et al., 2016c), and found that only $0.2 \mu \mathrm{g} / \mathrm{ml}$ of hemin was optimal for growth and production, despite the same requirement for reducing power as the RBDO strain in the current study. It is likely that this difference is due to differences between the media used. For the current study, we used SA medium, whereas we used rich M17 medium previously. M17 is prepared from various rich components such as meat/beef extract, peptone and 


\section{ACCEPTED MANUSCRIPT}

yeast extract (Terzaghi and Sandine, 1975) that could possibly contain some hemin, which could influence growth and production.

When comparing the two possible approaches for producing R-BDO, relying on either NOX or respiration, it appears that the latter is a preferred option. In our case, for L. lactis, respiration is more efficient than NOX. In addition, it could be more simple to adjust the reducing power available by controlling the hemin concentration than by adjusting oxygen tension, especially for large industrial fermenters.

\subsection{R-BDO production using a dual-phase fermentation approach}

As demonstrated above, by fine-tuning respiration, it is possible to adjust the reducing power available and thus ensure high yield production of R-BDO. For producing R-BDO, it should in principle be possible to use an even more simple approach involving two stages: 1) convert a part of the glucose into acetoin using a fully active respiration, and 2) convert acetoin and glucose in a redox balanced way into R-BDO (no aeration) (Fig. 6A). We decided to test whether this was possible, and designed a two-stage fermentation process. By monitoring glucose consumption and acetoin formation, it was possible to determine the theoretical operating point (TOP) for the switch from respiration to anaerobic fermentation, as the time point when the glucose-consumption curve crossed the acetoin-formation curve. We found that it was better to switch earlier than this TOP to allow for complete consumption of the dissolved $\mathrm{O}_{2}$ in the flask or fermenter. First the strategy was tested using strain RBDO in shake flasks in the presence of $3 \mu \mathrm{g} / \mathrm{ml}$ hemin, which was found to be sufficient to activate respiration completely (Fig. 5). After $3.5 \mathrm{~h}$, we changed the fermentation mode to anaerobic, and indeed the glucose and acetoin were co-consumed. Finally $41 \mathrm{mM}$ R-BDO was achieved from $54 \mathrm{mM}$ glucose with a yield of $76 \%$ of the theoretical maximum (Fig. 6B). We also 


\section{ACCEPTED MANUSCRIPT}

optimized the operating point, and found that when glucose was in 55\% molar excess of acetoin, switching was optimal to get the highest R-BDO yield (Table S5).

Recently, Liang et al., (Liang and Shen, 2017) devised a strategy where $15 \mathrm{~g} / \mathrm{L}$ glucose and $5 \mathrm{~g} / \mathrm{L}$ acetoin were co-fed to an $E$. coli mutant ( $\Delta l d h A \Delta a d h E \Delta f r d \mathrm{pKM} 3)$, which resulted in restored anaerobic growth and production of $3 \mathrm{~g} / \mathrm{L} \mathrm{m}-\mathrm{BDO}$. Although the co-feeding approach can allow for redox balance and decouple NADH-generation from glycolysis in the production pathway, this approach appears unfavorable due to the high cost of acetoin and is thereby incompatible with large scale production of BDO. In addition, Liang et al. found that acetoin was quite toxic for $E$. coli. In a previous study, we also observed the growth hampering effect of acetoin on L. lactis, and found that $20 \mathrm{~g} / \mathrm{L}$ acetoin decreased the growth rate of L. lactis by $50 \%$ (Kandasamy et al., 2016). The switch strategy we have developed here appears to be an improvement, as it can allow for growth to a high cell density under respiratory conditions using cheap glucose, and then in the anaerobic phase, the toxic acetoin and the remaining glucose are efficiently converted into R-BDO, where fast growth is less important.

\subsection{Efficient R-BDO production in bioreactors using the two-developed strategies}

We tested the two strategies used for producing R-BDO in shake flasks using a relatively low concentration of glucose. To investigate the scalability of the approaches, we decided to test the two strategies using bioreactors and medium containing a higher glucose concentration. For strategy I, which is fine-tuning of respiration capacity, we first optimized hemin concentrations for the RBDO strain in the presence of $445 \mathrm{mM}$ glucose $(80 \mathrm{~g} / \mathrm{L})$. As shown in Fig. 7A, when the hemin concentration was set at $1.6 \mu \mathrm{g} / \mathrm{ml}$, we observed that R-BDO was the dominant product, and the

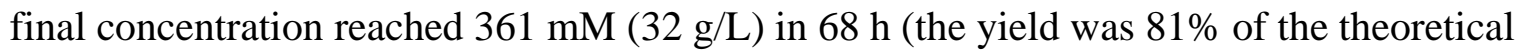
maximum). Minor amounts of acetoin were detectable during the fermentation process, but not after complete consumption of glucose. We also tested other hemin concentrations, $1.0 \mu \mathrm{g} / \mathrm{ml}$ and 2.0 


\section{ACCEPTED MANUSCRIPT}

$\mu \mathrm{g} / \mathrm{ml}$, and the results are shown in Fig. S2. At $1.0 \mu \mathrm{g} / \mathrm{ml}$ hemin, the final cell density $\mathrm{OD}_{600}$ only reached 5.9, which was significantly lower than that of 9.1 achieved with $1.6 \mu \mathrm{g} / \mathrm{ml}$. At this latter hemin concentration, not all the glucose could be consumed and this resulted in a lower R-BDO titer of $217 \mathrm{mM}(19.5 \mathrm{~g} / \mathrm{L})($ Fig. S2A). At $2.0 \mu \mathrm{g} / \mathrm{ml}$ of hemin, the final biomass density reached $10.5\left(\mathrm{OD}_{600}\right)$ and $310 \mathrm{mM}$ R-BDO $(28 \mathrm{~g} / \mathrm{L})$ was produced in addition to $62 \mathrm{mM}(5.4 \mathrm{~g} / \mathrm{L})$ of acetoin (Fig. S2B). Under the conditions applied, $1.6 \mu \mathrm{g} / \mathrm{ml}$ was the most suitable level for R-BDO production.

For strategy II, which is the switch from respiration to anaerobic fermentation, we used $5 \mu \mathrm{g} / \mathrm{ml}$ of hemin for the fully-active respiration and then switched to anaerobic fermentation at around $25 \mathrm{~h}$ by aerating with $\mathrm{N}_{2}$ for $0.5 \mathrm{~h}$ followed by no-aeration. We noticed that glucose and acetoin both could be consumed anaerobically, thus giving rise to R-BDO. The final concentration of R-BDO was 365 $\mathrm{mM}(33 \mathrm{~g} / \mathrm{L})$ with a yield of $82 \%$ of the theoretical maximum.

We achieved high yield production of R-BDO using both strategies and believe that each of them is suitable for producing R-BDO and other interesting chemicals, for which the amount of reducing power needs to be adjusted. Future work could include introducing the hemin biosynthetic pathway into L. lactis, which then could be finely controlled by using systems metabolic engineering approaches (Lee and Kim, 2015), and thereby adding hemin to the medium could be avoided.

\section{Conclusion}

We have created an L. lactis platform, AceN (MG1363 $\left.\Delta^{3} l d h \Delta p t a \Delta a d h E \Delta b u t B A \Delta n o x E\right)$, that relies on respiration in order to be able to grow, and where respiration can be fine-tuned by adjusting the hemin concentration in the growth medium. This platform appears useful for producing various useful chemicals, the biosynthesis of which require different amounts of reducing power. We used this platform for producing a high titer and high yield of acetoin by using its 


\section{ACCEPTED MANUSCRIPT}

maximal respiration capacity. By introducing an R-BDO forming butanediol dehydrogenase, and by adjusting the respiration capacity, we achieved efficient R-BDO production. Finally, we developed a two-stage fermentation approach for producing R-BDO. These strategies demonstrate that controlling the respiration capacity is a good way to adjust the reducing power available for chemicals production.

\section{Competing financial interests}

The authors declare no competing financial interests.

\section{Acknowledgements}

We thank J. Chen for donating the plasmid proGFP. We thank Timothy John Hobley for critically reading the manuscript. This work was supported by a grant from the Innovation fund Denmark (4106-00037B).

\section{References}

Baek, S., Kwon, E. Y., Kim, Y. H., Hahn, J., 2016. Metabolic engineering and adaptive evolution for efficient production of D-lactic acid in Saccharomyces cerevisiae. Appl. Microbiol. Biotechnol. 100, 2737-2748.

Biswas, R., Yamaoka, M., Nakayama, H., 2012. Enhanced production of 2,3-butanediol by engineered Bacillus subtilis. Appl. Microbiol. Biotechnol. 94, 651-658.

Blank, L. M., Koebmann, B. J., Michelsen, O. L. E., Nielsen, L. K., 2001. Hemin reconstitutes proton extrusion in an H-ATPase-negative mutant of Lactococcus lactis. Appl. Environ. Microbiol. 183, 6707-6709.

Cannon, M. B., Remington, S. J., 2006. Re-engineering redox-sensitive green fluorescent protein for improved response rate. Protein Sci. 15, 45-57.

Chen, J., Shen, J., Solem, C., Jensen, P. R., 2013. Oxidative stress at high temperatures in Lactococcus lactis due to an insufficient supply of riboflavin. Appl. Environ. Microbiol. 79, 6140-6147.

Choi, Y. J., Lee, J., Jang, Y., Lee, S. Y., 2014. Metabolic engineering of microorganisms for the production of higher alcohols. MBio 5, e01524-14. 
Cocaign-bousquet, M., Garrigues, C., Loubiere, P., Lindley, N. D., 1996. Physiology of pyruvate metabolism in Lactococcus lactis. Antonie van Leeuwenhoe 70, 253-267.

Duwat, P., Sourice, S., Cesselin, B., Lamberet, G., Vido, K., Gaudu, P., Loir, Y. L. E., Violet, F., Loubiere, P., Gruss, A., 2001. Respiration capacity of the fermenting bacterium Lactococcus lactis and its positive effects on growth and survival. J. Bacteriol. 183, 4509-4516.

Fu, J., Wang, Z., Chen, T., Liu, W., Shi, T., Wang, G., Tang, Y., Zhao, X., 2014. NADH plays the vital role for chiral pure D-2,3-butanediol production in Bacillus subtilis under limited oxygen conditions. Biotechnol. Bioeng. 111, 2126-2131.

Garrigues, C., Johansen, E., Pedersen, M.B., Møllgaard, H., Sørrensen K., Gaudu, P., Gruss, A. Lamberet, G., 2006. Getting high (OD) on heme. Nat. Rev. Microbiol. 4, c2.

Gaspar P, Neves AR, Gasson MJ, Shearman CA, Santos H. 2011. High yields of 2,3-butanediol and mannitol in Lactococcus lactis through engineering of $\mathrm{NAD}^{+}$cofactor recycling. Appl. Environ. Microbiol. 77:6826-6835.

Gasson, M. J., 1983. Plasmid complements of Streptococcus lactis NCDO 712 and other Lactic streptococci after protoplast-induced curing. J. Bacteriol. 154, 1-9.

Geu-Flores, F., Nour-Eldin, H. H., Nielsen, M. T., Halkier, B. A., 2007. USER fusion: a rapid and efficient method for simultaneous fusion and cloning of multiple PCR products. Nucleic Acids Res. 35, e55.

Hasegawa, S., Suda, M., Uematsu, K., Natsuma, Y., Hiraga, K., Jojima, T., Inui, M., Yukawa, H., 2013. Engineering of Corynebacterium glutamicum for high-yield L-valine production under oxygen deprivation conditions. Appl. Environ. Microbiol. 79, 1250-1257.

Holo, H., Nes, I. F., 1989. High-frequency transformation, by electroporation, of Lactococcus lactis subsp. cremoris grown with glycine in osmotically stabilized media. Appl. Environ. Microbiol. $55,3119-3123$.

Jensen, P. R., Hammer, K., 1993. Minimal requirements for exponential growth of Lactococcus lactis. Appl. Environ. Microbiol. 59, 4363-4366.

Kandasamy, V., Liu, J. M., Dantoft, S. H., Solem, C., Jensen, P. R., 2016. Synthesis of (3R)-acetoin by metabolically engineered Lactococcus lactis. Sci. Rep. 6, 36769.

Kim, S., Hahn, J., 2015. Efficient production of 2,3-butanediol in Saccharomyces cerevisiae by eliminating ethanol and glycerol production and redox rebalancing. Metab. Eng. 31, 94-101.

Kim, T., Park, J., Kim, H., Cho, K., Lee, S. Y., 2015. Design of homo-organic acid producing strains using multi-objective optimization. Metab. Eng. 28, 63-73.

Kleerebezem, M., Hols, P., Hugenholtz, J., 2000. Lactic acid bacteria as a cell factory: rerouting of carbon metabolism in Lactococcus lactis by metabolic engineering. Microb. Cell Fact. 26, 840-848.

Koebmann, B., Blank, L. M., Solem, C., Petranovic, D., Nielsen, L. K., Jensen, P. R., 2008. Increased biomass yield of Lactococcus lactis during energetically limited growth and respiratory conditions. Biotechnol. Appl. Biochem. 33, 25-33. 
Koebmann, B., Nilsson, D., Kuipers, O. P., Jensen, P. R., 2000. The membrane-bound H-ATPase complex is essential for growth of Lactococcus lactis. J. Bacteriol. 182, 4738-4743.

Kumar, S., Bandyopadhyay, U., 2005. Free heme toxicity and its detoxification systems in human. Toxicol. Lett. 157, 175-188.

Lane, N., 2010. Why are cells powered by proton gradients? Nature Education 3, 18.

Lechardeur, D., Cesselin, B., Liebl, U., Vos, M. H., Fernandez, A., Brun, C., Gruss, A., Gaudu, P., 2012. Discovery of intracellular heme-binding protein HrtR, which controls heme efflux by the conserved HrtB-HrtA transporter in Lactococcus lactis. J. Biol. Chem. 287, 4752-4758.

Lee, S. Y., Kim, H. U., 2015. Systems strategies for developing industrial microbial strains. Nat. Biotechnol. 33, 1061-1072.

Li, L., Li, K., Wang, Y., Chen, C., Xu, Y., Zhang, L., Han, B., Gao, C., Tao, F., Ma, C., Xu, P., 2015. Metabolic engineering of Enterobacter cloacae for high-yield production of enantiopure (2R, 3R)-2,3-butanediol from lignocellulose-derived sugars. Metab. Eng. 28, 19-27.

Li, Z., Jian, J., Wei, X., 2010. Microbial production of meso-2,3-butanediol by metabolically engineered Escherichia coli under low oxygen condition. Appl. Microbiol. Biotechnol. 87, 2001-2009.

Lian, J., Chao, R., Zhao, H., 2014. Metabolic engineering of a Saccharomyces cerevisiae strain capable of simultaneously utilizing glucose and galactose to produce enantiopure. Metab. Eng. 23, 92-99.

Liang, K., Shen, C. R., 2017. Selection of an endogenous 2,3-butanediol pathway in Escherichia coli by fermentative redox balance. Metab. Eng. 39, 181-191.

Liu, J., Hung, S., Chan, J., Brock-nannestad, T., Chen, J., Lee, S. Y., Solem, C., Jensen, P. R., 2016a. Combining metabolic engineering and biocompatible chemistry for high-yield production of homo-diacetyl and homo-(S,S)-2,3-butanediol. Metab. Eng. 36, 57-67.

Liu, J., Kandasamy, V., Würtz, A., Jensen, P. R., Solem, C., 2016b. Stimulation of acetoin production in metabolically engineered Lactococcus lactis by increasing ATP demand. Appl. Microbiol. Biotechnol. 100, 9509-9517.

Liu, J., Solem, C., Jensen, P. R., 2016c. Integrating biocompatible chemistry and manipulating cofactor partitioning in metabolically engineered Lactococcus lactis for fermentative production of (3S)-Acetoin. Biotechnol. Bioeng. 113, 2744-2748.

Maresso, A. W., Schneewind, O., 2006. Iron acquisition and transport in Staphylococcus aureus. Biometals. 19, 193-203.

Melchiorsen, R., Jokumsen, V., Villadsen, J., Israelsen, H., Arnau, J., 2002. The level of pyruvateformate lyase controls the shift from homolactic to mixed-acid product formation in Lactococcus lactis. Appl. Microbiol. Biotechnol. 58, 338-344.

Nielsen, J., Keasling, J., 2016. Engineering cellular metabolism. Cell. 164, 1185-1197. 
Pedersen, M. B., Gaudu, P., Lechardeur, D., 2012. Aerobic respiration metabolism in lactic acid bacteria and uses in biotechnology. Annu. Rev. Food Sci. Technol. 3, 37-58.

Shen, C. R., Lan, E. I., Dekishima, Y., Baez, A., Cho, K. M., Liao, J. C., 2011. Driving forces enable high-titer anaerobic 1-butanol synthesis in Escherichia coli. Appl. Environ. Microbiol. 77, 2905-2915.

Solem, C., Defoor, E., Jensen, P. R., Martinussen, J., 2008. Plasmid pCS1966, a new selection/counterselection tool for Lactic Acid Bacterium strain construction based on the oroP gene, encoding an orotate transporter from Lactococcus lactis. Appl. Environ. Microbiol. 74, 4772-4775.

Solem, C., Dehli, T., Jensen, P. R., 2013. Rewiring Lactococcus lactis for ethanol production. Appl. Environ. Microbiol. 79, 2512-2518.

Stephanopoulos, G., 2007. Challenges in engineering microbes for biofuels production. Science. $315,801-805$.

Terzaghi, B. E., Sandine, A. W. E., 1975. Improved medium for Lactic streptococci and their bacteriophages. Appl. Microbiol. 29, 807-813.

Tachon, S., Brandsma, J. B., Yvon, M., 2010. NoxE NADH oxidase and the electron transport chain are responsible for the ability of Lactococcus lactis to decrease the redox potential of milk. Appl. Environ. Microbiol. 76, 1311-1319.

Teusink, B., Bachmann, H., Molenaar, D., 2011. Systems biology of lactic acid bacteria: a critical review. Microb. Cell Fact. 10, 1-17.

Wang, Q., Chen, T., Zhao, X., Chamu, J., 2012. Metabolic engineering of thermophilic bacillus licheniformis for chiral pure D-2,3-butanediol production. Biotechnol. Bioeng. 109, 16101621.

Wei, N., Quarterman, J., Kim, S. R., Cate, J. H. D., Jin, Y., 2013. Enhanced biofuel production through coupled acetic acid and xylose consumption by engineered yeast. Nat. Commun. $4,1-$ 8.

Xu, Y., Chu, H., Gao, C., Tao, F., Zhou, Z., Li, K., Li, L., 2014. Systematic metabolic engineering of Escherichia coli for high-yield production of fuel bio-chemical 2,3-butanediol. Metab. Eng. $23,22-33$.

Yan, Y., Lee, C., Liao, J. C., 2009. Enantioselective synthesis of pure $(R, R)$-2,3-butanediol in Escherichia coli with stereospecific secondary alcohol dehydrogenases. Org. Biomol. Chem. 7, 3914-3917.

Zhang, X., Zhang, R., Bao, T., Rao, Z., Yang, T., Xu, M., Xu, Z., Li, H., Yang, S., 2014. The rebalanced pathway significantly enhances acetoin production by disruption of acetoin reductase gene and moderate-expression of a new water-forming NADH oxidase in Bacillus subtilis. Metab. Eng. 23, 34-41.

Zhu, J., Sanchez, A., Bennett, G., San, K. Y., 2011. Manipulating respiratory levels in Escherichia coli for aerobic formation of reduced chemical products. Metab. Eng. 13, 704-712. 
Figure 1. Respiration couples the production of acetoin or R-BDO. The cross symbol indicates competing pathways that have been inactivated. The complete respiratory chain in L. lactis is comprised of $\mathrm{NADH}$ dehydrogenase (NoxAB), menaquinone pools $\left(\mathrm{mQ}, \mathrm{mQH}_{2}\right)$ and cytochrome oxidase (Cyt bd). In order for the cytochrome oxidase to be functional, an exogenous supply of hemin is needed. Abbreviations: Als, $\alpha$-acetolactate synthase; AldB, $\alpha$-acetolactate decarboxylase; NoxE, NADH oxidase; BsBdh, butanediol dehydrogenase (BdhA) from B. subtilis.

Figure 2. Effect of the hemin concentration on the cellular performance of L. lactis MG1363. MG1363 was cultivated in defined SA medium with $25 \mathrm{mM}$ glucose. Hemin is an iron-containing protoporphyrin and essential cofactor of cytochrome oxidase in L. lactis. Respiration becomes active once hemin is available from the environment.

Figure 3. Characterization of the respiration-dependent strain AceN. AceN (MG1363 $\Delta^{3} l d h$ $\triangle p t a \triangle a d h E \triangle b u t B A \triangle n o x E)$ was cultivated in the presence of $43 \mathrm{mM}$ glucose for (A)-(C) in shake flasks. (A) The growth of strain AceN is hemin-dependent. (B) Comparison of the fermentation performance of strain AceN on $1 \mu \mathrm{g} / \mathrm{ml}(1 \mathrm{H})$ or $2 \mu \mathrm{g} / \mathrm{ml}$ hemin $(2 \mathrm{H})$. (C) The NADH/NAD ${ }^{+}$ratio as a function of hemin concentrations. (D) The effect of hemin levels on cellular growth at a high glucose concentration ( $450 \mathrm{mM}$ glucose). Experiments were conducted in duplicates, and error bars indicate standard deviations.

Figure 4. Efficient production of acetoin in the presence of respiration in bioreactors. The initial glucose concentration was $450 \mathrm{mM}(81 \mathrm{~g} / \mathrm{L})$ for both strains Ace001 and AceN. (A) The 


\section{ACCEPTED MANUSCRIPT}

fermentation of strain Ace001 without respiration. (B) The fermentation of strain AceN in the presence of $5 \mu \mathrm{g} / \mathrm{ml}$ hemin. Experiments were conducted in duplicates and error bars indicate standard deviations.

Figure 5. Fine-tuning respiration capacity for R-BDO biosynthesis. The cultivation of strain RBDO (MG1363 $\Delta^{3} l d h \Delta p t a \Delta a d h E \Delta b u t B A \Delta$ noxE pJM002) was performed in shake flasks with $54 \mathrm{mM}$ glucose. (A) Growth of RBDO was hemin-dependent. (B) High-yield production of R-BDO on $1 \mu \mathrm{g} / \mathrm{ml}(1 \mathrm{H})$. The nested figure shows the fermentation and product profile at $3 \mu \mathrm{g} / \mathrm{ml}(3 \mathrm{H})$. Experiments were conducted in duplicates and error bars indicate standard deviations.

Figure 6. The switch from respiration to anaerobic fermentation for high-yield production of R-BDO. (A) The stoichiometric balance of cofactors by using equal mole of glucose and acetoin under anaerobic conditions. (B) Batch fermentation of strain RBDO. The dashed line indicates the operating point for the switch from respiration to anaerobic fermentation. Phase I, fully active respiration. Shake flask fermentation was performed with the filling volume of $30 \mathrm{ml}$ in $250-\mathrm{ml}$ flasks at the speed of $200 \mathrm{rpm}$, and the initial glucose concentration was $54 \mathrm{mM}$. Phase II, anaerobic fermentation. The $30 \mathrm{ml}$ fermentation broth was immediately transferred to $50 \mathrm{ml}$ sealed tubes and was put in the static condition (slow-magnetic stirring to keep homogeneous). Experiments were conducted in duplicates and error bars indicate standard deviations.

Figure 7. Comparison of two strategies used for producing R-BDO in bioreactors. (A) Finetuning of respiration of strain RBDO with a hemin concentration of $1.6 \mu \mathrm{g} / \mathrm{ml}$. (B) The switch from fully active respiration to anaerobic fermentation. The hemin level was $5 \mu \mathrm{g} / \mathrm{ml}$. The dashed line indicated the operating point and before that, the aeration rate was $1.0 \mathrm{vvm}$ of air and after that the culture was sparged with $1.0 \mathrm{vvm}$ of $\mathrm{N}_{2}$ for $0.5 \mathrm{~h}$ and then followed by no aeration. 
Table 1. Strains and plasmids

\begin{tabular}{|c|c|c|}
\hline Designation & Genotype or description & Reference \\
\hline \multicolumn{3}{|c|}{ L. lactis strains } \\
\hline MG1363 & The wild type & Gasson, 1983 \\
\hline CS4363 & MG1363 $\Delta^{3} l d h \Delta p t a \Delta a d h E$ & Solem et al., 2013 \\
\hline Ace001 & MG1363 $\Delta^{3} l d h \triangle p t a \triangle a d h E \Delta b u t B A$ & Liu et al., 2016 \\
\hline Ace002 & MG1363 $\Delta^{3} l d h \Delta p t a \Delta a d h E \Delta b u t B A$ pCS4564 & This work \\
\hline Ace003 & MG1363 $\Delta^{3} l d h \triangle p t a \Delta a d h E \Delta b u t B A \Delta$ noxE pCS4564 & This work \\
\hline AceN & MG1363 $\Delta^{3} l d h \triangle p t a \triangle a d h E \Delta b u t B A \Delta n o x E$ & This work \\
\hline RBDO & MG1363 $\Delta^{3} l d h \Delta p t a \Delta a d h E \Delta b u t B A \Delta n o x E$ pJM002 & This work \\
\hline Ace001R & MG1363 $\Delta^{3} l d h \triangle p t a \Delta a d h E \Delta b u t B A$ proGFP & This work \\
\hline AceNR & MG1363 $\Delta^{3}$ ldh $\Delta$ pta $\triangle a d h E \Delta b u t B A \Delta$ noxE proGFP & This work \\
\hline \multicolumn{3}{|l|}{ Plasmids } \\
\hline pG host8 & E. coli/L. lactis shuttle vector, $\mathrm{Tet}^{\mathrm{R}}$, thermosensitive & Maguin et al., 1996 \\
\hline pCS4564 & $\mathrm{pG}^{+}$host8::SP-ldhA (E. coli) & Liu et al., 2016 \\
\hline pTD6 & A derivative of pAK 80 containing a gusA repor & Solem et al., 2013 \\
\hline proGFP & For expression of roGFP-R12 & Chen et al., 2013 \\
\hline pCS4257 & For knocking out noxE & This work \\
\hline pJM002 & pTD6::bdhA (Bacillus subtilis) & This work \\
\hline
\end{tabular}

\section{Highlights}

- A novel L. lactis platform allowing for fine-tuning of the reducing power availability via respiration

- Respiration capacity modulated through hemin concentration

- High titer and yield production of acetoin by harnessing respiration

- High titer and yield production of the $(R, R)$-stereoisomer of 2,3-butanediol, either using a finetuned respiration or by using a dual-phase fermentation approach 


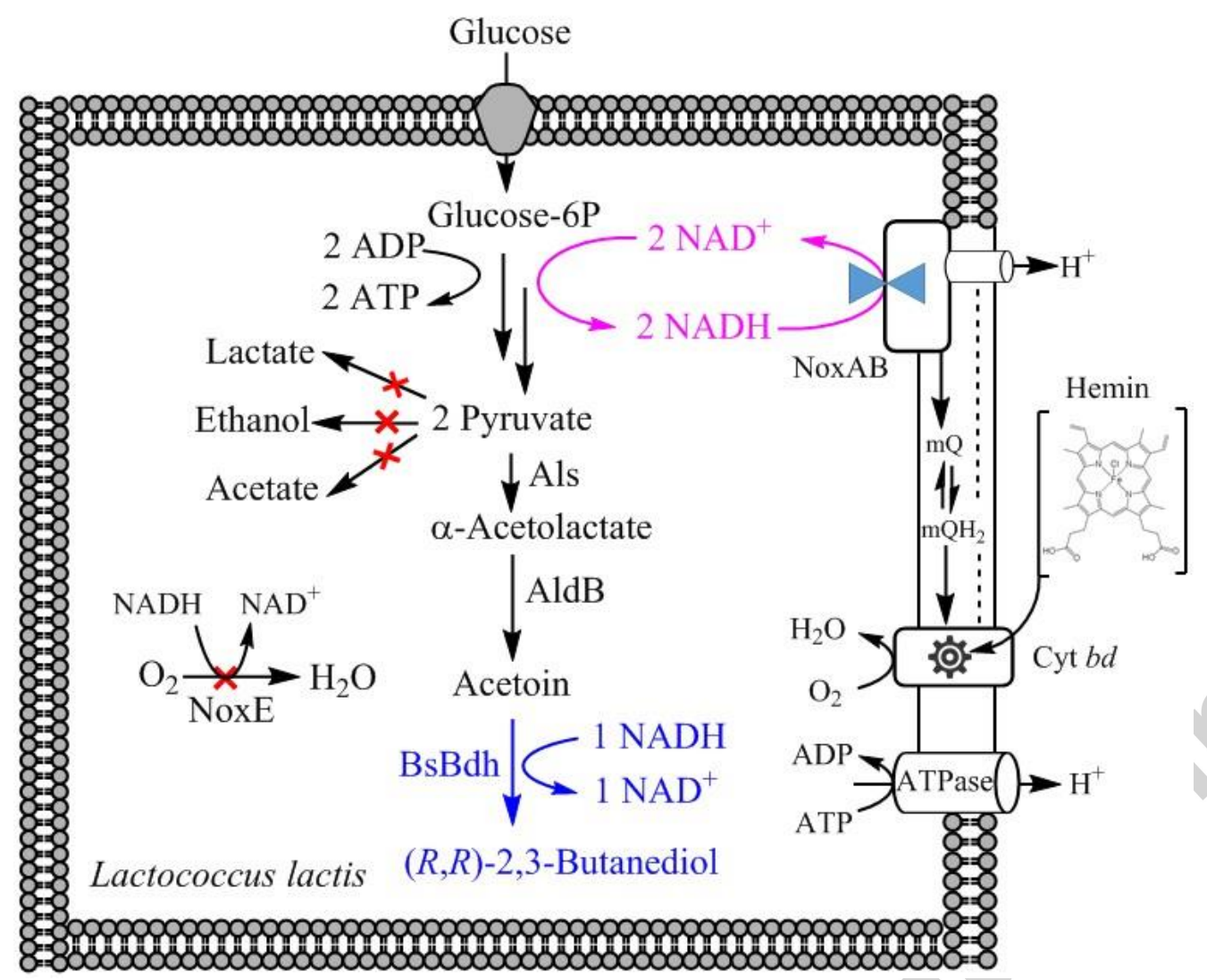




\section{ACCEPTED MANUSCRIPT}

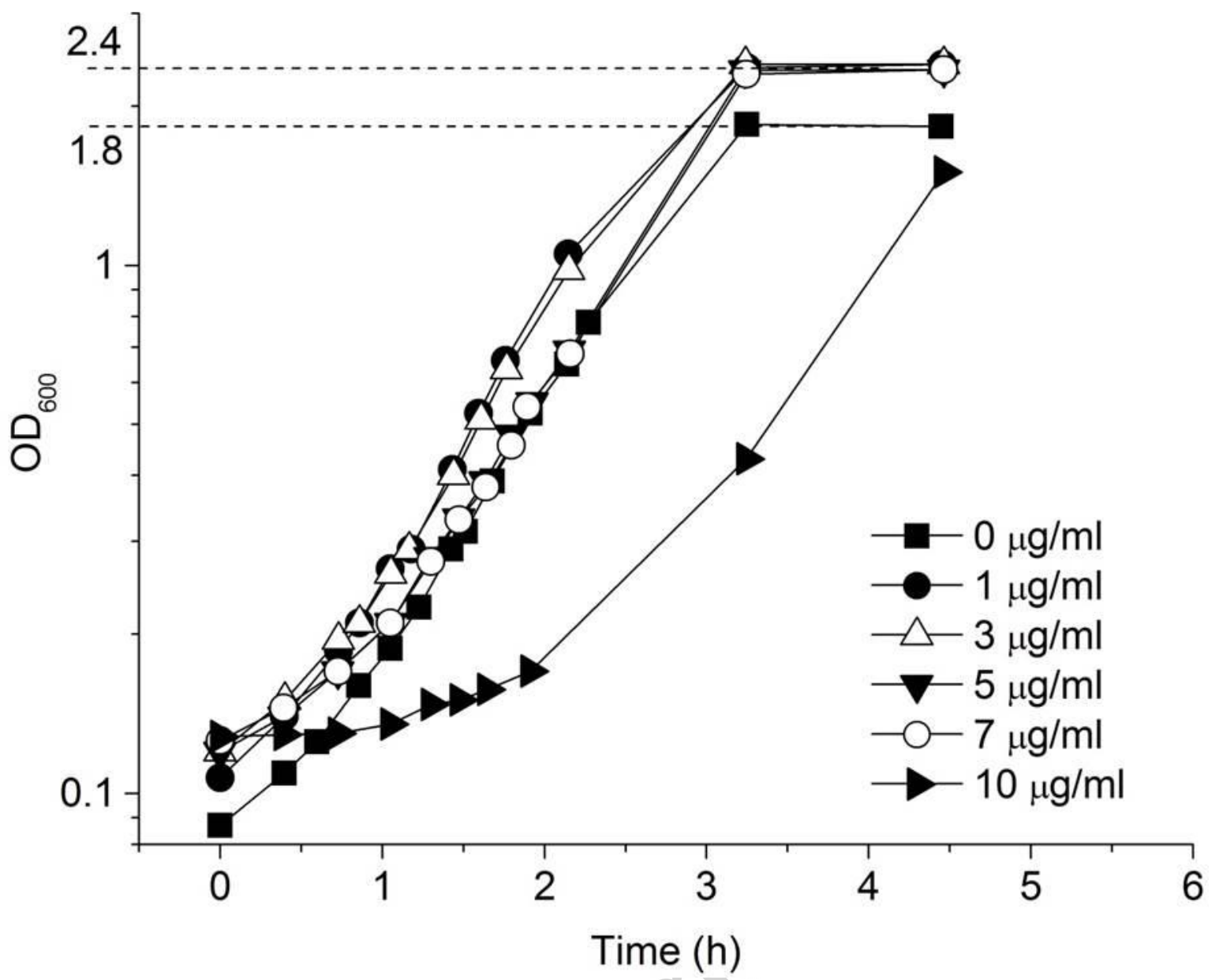


A

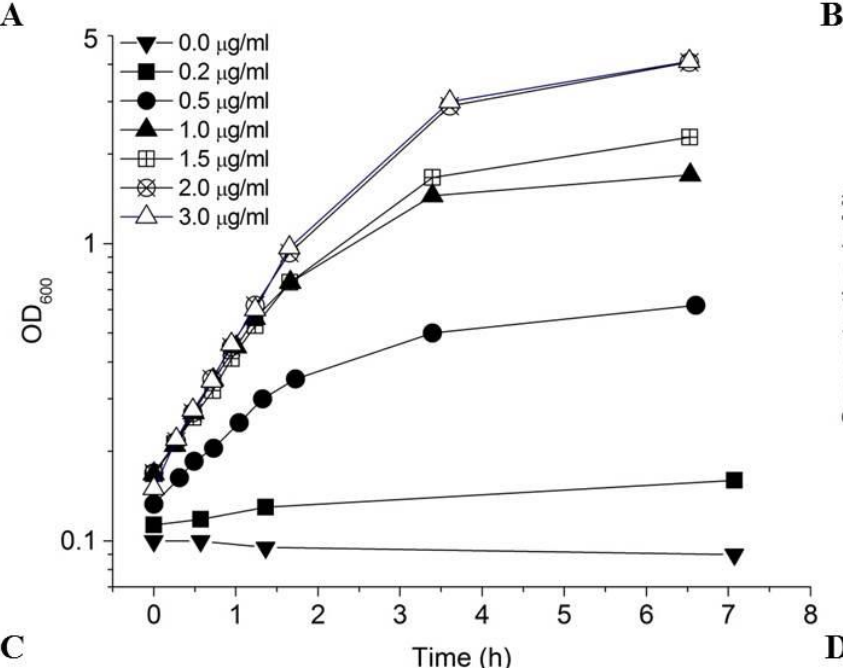

C

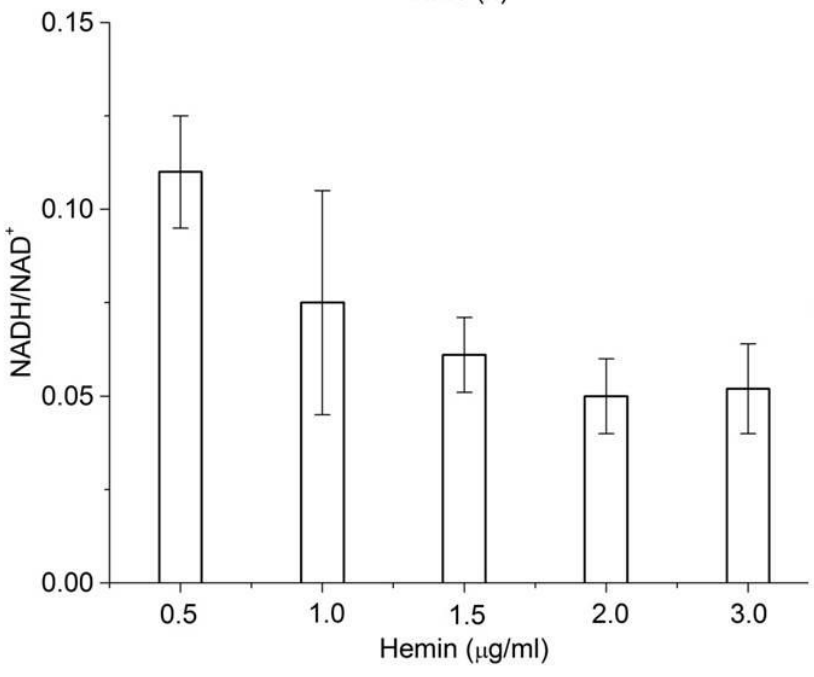

B
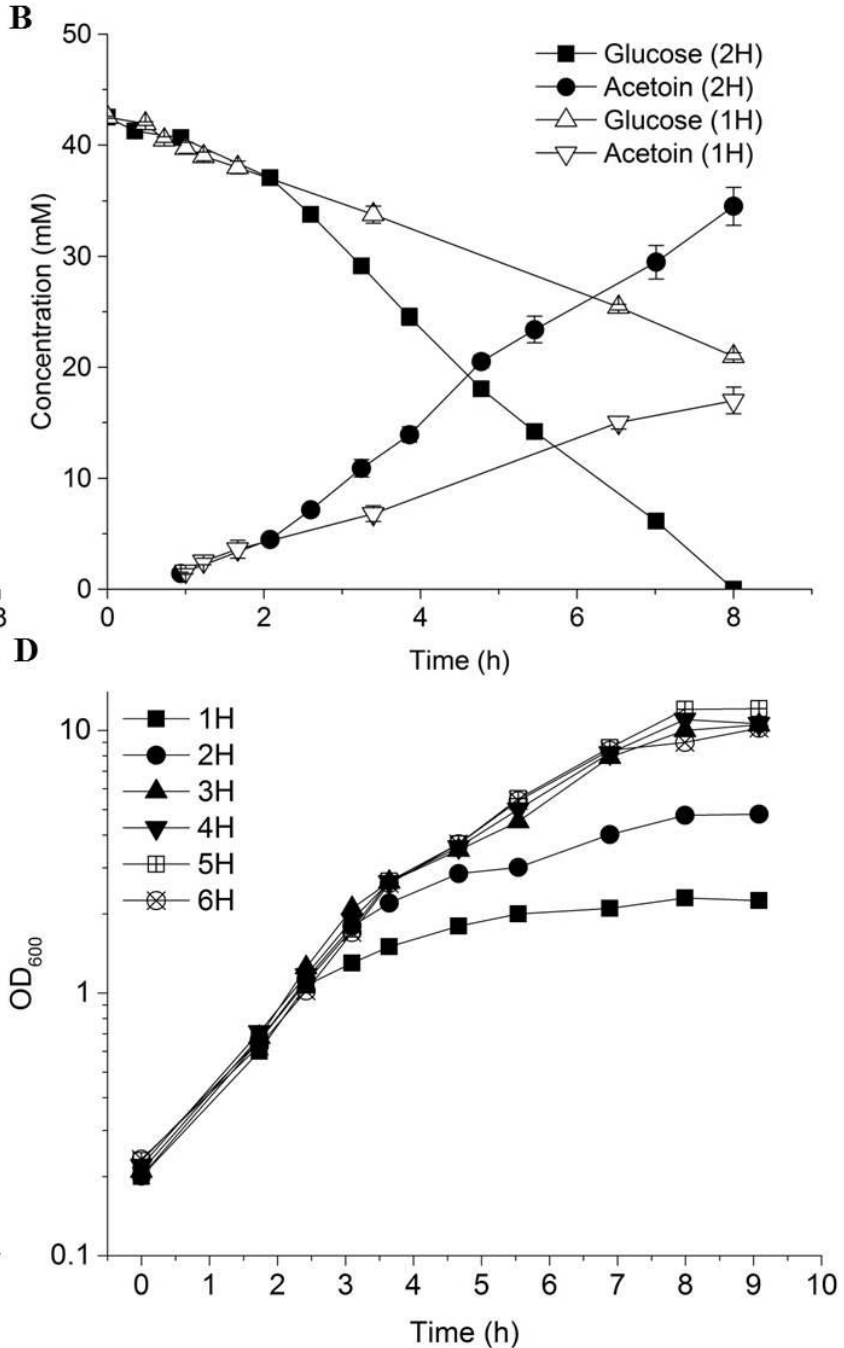

A

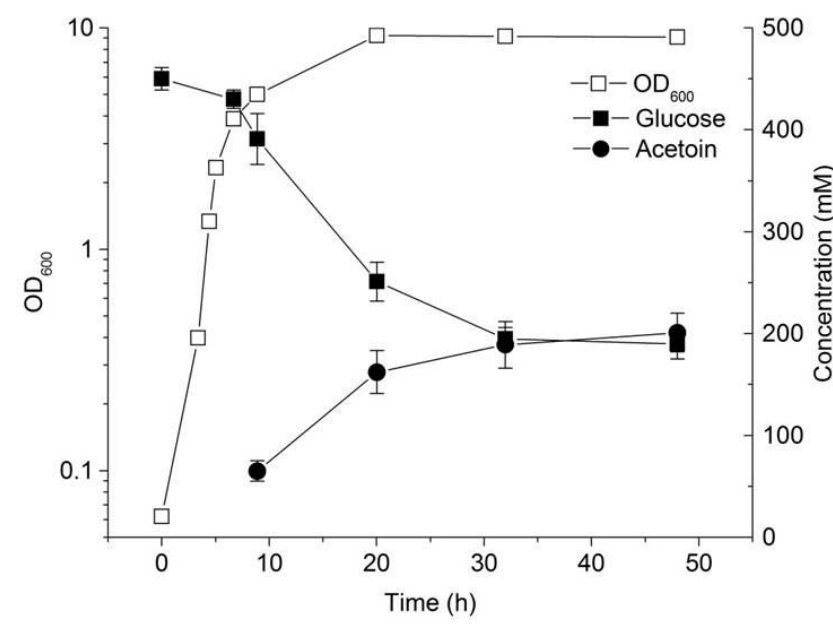

B

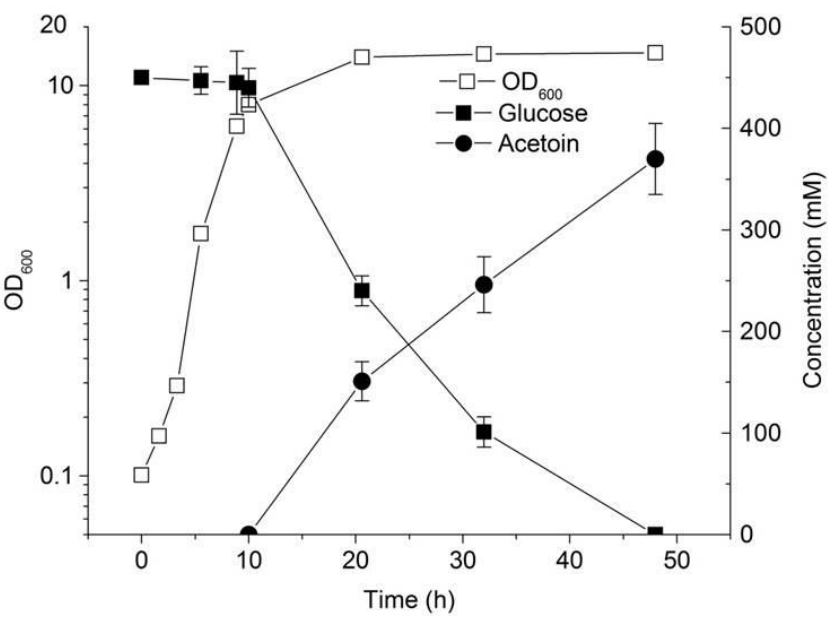


A

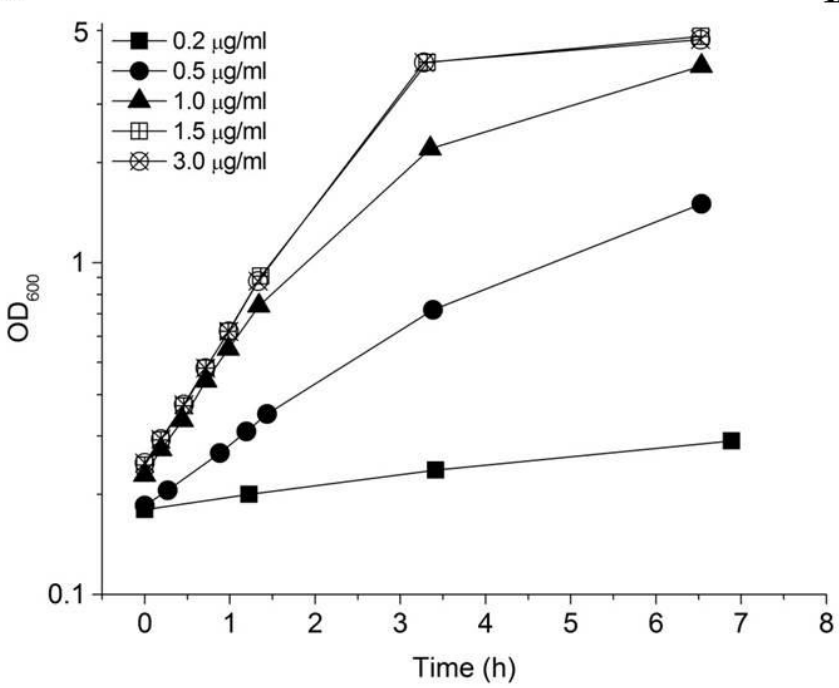

B

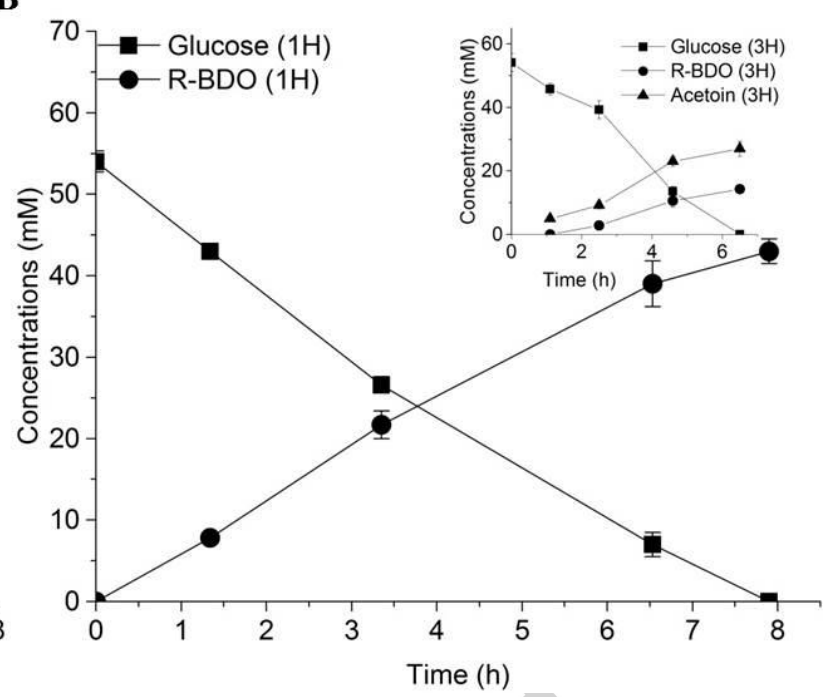

A
a Glucose
a Acetoin

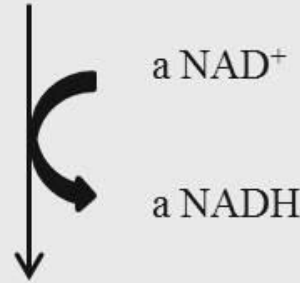
a R-BDO
a R-BDO

B

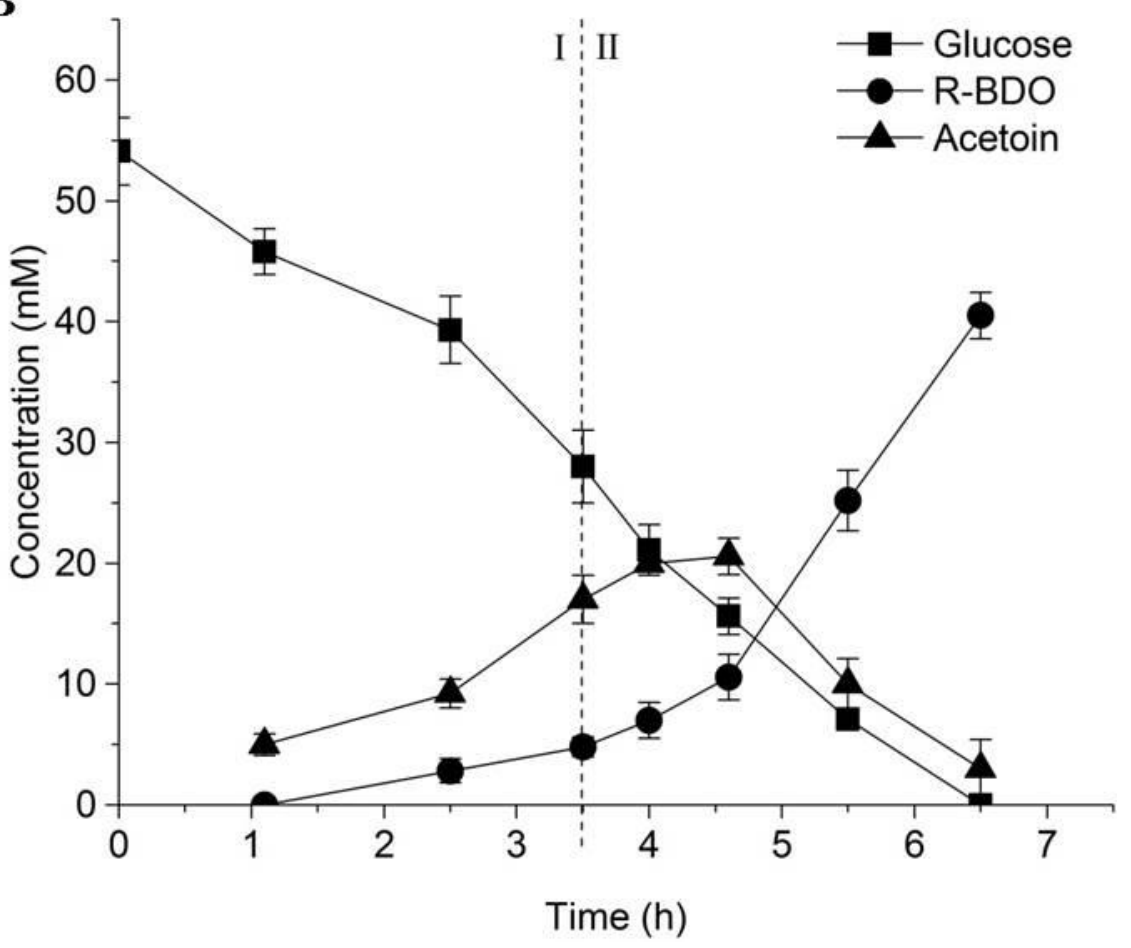




\section{ACCEPTED MANUSCRIPT}

A

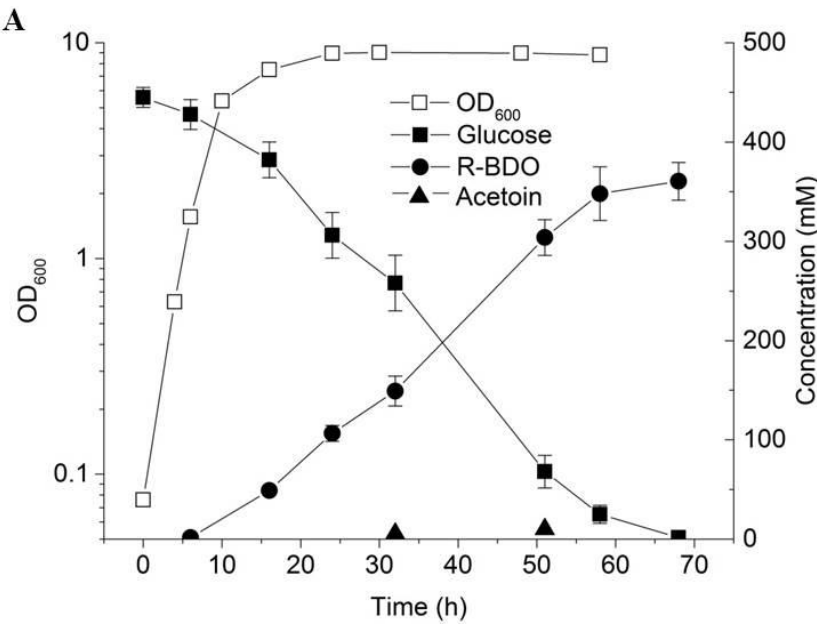

B

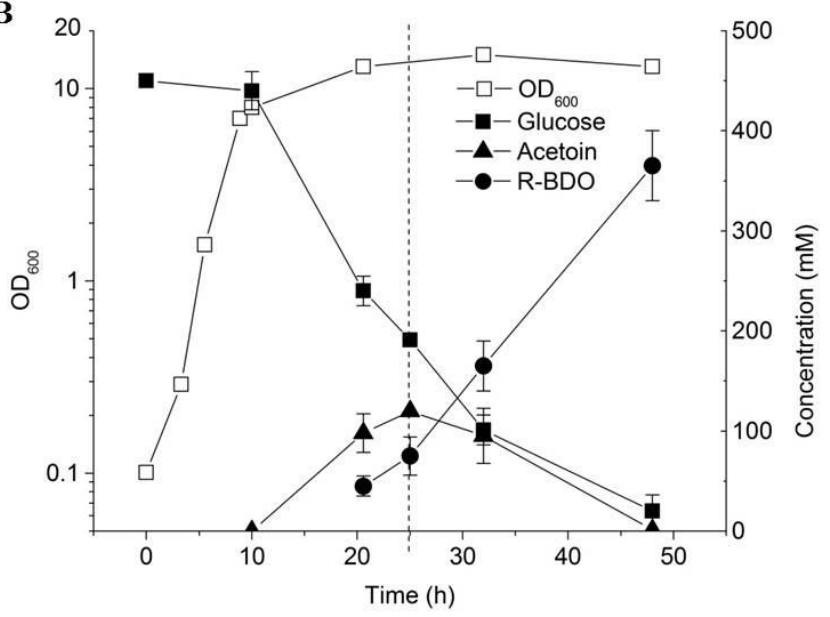

